\title{
A review of hot climate concreting, and the appropriate procedures for ordinary jobsites in developing countries
}

\author{
Nabil Bella ${ }^{1, *}$, Ilham Aguida Bella $^{1}$, and Aissa Asroun ${ }^{2}$ \\ ${ }^{1}$ FIMAS Laboratory of reliability of materials and structures in south, Tahri Mohamed University, \\ B.P. 417, 08000, Béchar, Algeria \\ ${ }^{2}$ LGCE Laboratory of civil engineering and environment, Djillali Liabes University, BP 89, 22000. \\ Sidi Bel Abbés, Algérie
}

\begin{abstract}
Hot weather concreting involves some procedures to reduce negative effects caused principally by excessive water evaporation from the concrete surface. Potential problems for fresh concrete are: increased demand for water, increased the tendency the rate of slump loss corresponding to add water on job-site, an increased in execution rate, increased tendency for plastic shrinkage cracking and increased difficulty in controlling occluded air. Potential problems for hardened concrete may include: reduction of resistance at 28 days and long-term resulting of higher water demand and/or higher temperature of concrete, decreased durability resulting from cracking. Most developing countries have hot climate, ordinary jobsites in developing countries are characterised by reduced of human resources, equipment and infrastructures. This paper briefly reviews hot climate concreting procedures, especially the latest research in developing countries, and discusses the most appropriate in developing countries.
\end{abstract}

\section{Introduction}

Hot climate concrete is when the concrete is mixed, transporting, and pured in an elevated ambient temperature, low humidity and under solar radiation or exposed to the wind; Or any combination of the above-mentioned climatic conditions, which tends to deteriorate the qualities of the hardened or hardened concrete by the acceleration of the rate of water loss or the rate of hydration of the cement, which requires precautions To be taken, is defined the concreting in the hot climate by the ACI 305. Other standards, in order to avoid hot climate problems, impose a maximum limit of temperature. For example, BS 8110: Part 1: 1985 (British standard), at placing time no part of the concrete must have a temperature exceeding $30^{\circ} \mathrm{C}$, and the desirable value is generally $27^{\circ} \mathrm{C}$. ASTM C 94 (AASHTO-M157) for ready-mix concrete, also give a limit of the temperature of the concrete when casting between $29^{\circ} \mathrm{C}$ and $32^{\circ} \mathrm{C}$.

\footnotetext{
${ }^{*}$ Corresponding author: bella5dz@yahoo.fr
} 
ACI 305 (hot climate concreting) does not impose any limit for temperature of concrete, it considers that hot-weather concreting is more complex to be simplified at concrete placing temperature or delivery temperature, because durability is a general term and difficult to be quantified, but which can be perceived by the sense of the resistance of the concrete to the climatic actions.

In some works in southwestern USA concreting is prohibited in extremely hot weather in the summer months. In Arabian golf countries, where the annual amber temperature is generally between $10{ }^{\circ} \mathrm{C}$ and $50{ }^{\circ} \mathrm{C}$. In the period between June and September, the permissible maximum concrete temperature is usually between $35^{\circ} \mathrm{C}$ and $38^{\circ} \mathrm{C}$. Some authors $[2,3]$ consider the climate in Arab golf as an extremely hot climate.

This article focus on the effects of the hot climate on the concrete characteristics and the procedures of hot weather concreting based on important standards on this field: ACI, ASTM and AASHTO, and other important references; finally, conclusion of recommendations to improve ordinary construction practices in developed countries will be done.

\section{Effects of hot climate concreting}

\subsection{Water demand and slump loss}

The loss of workability is due to double action of evaporation of water and heat of hydration. This can lead to a tendency to compensate the lack of workability by the addition of water with detrimental consequences to the resistance [5,6] and durability [6]. Other research shows that increasing the $\mathrm{E} / \mathrm{C}$ ratio with an adequate cure improves resistance [7]. Increasing the mixing water also results in increased drying shrinkage.

\subsection{Excessive evaporation}

ACI Committee 305 indicate that precautions to remedy plastic shrinkage should be taken if the evaporation rate approaches $1 \mathrm{~kg} / \mathrm{m}^{2} / \mathrm{h}$, this rate is estimated from the ACI 305 nomograph (Fig. 1).

Although this diagram has been criticized [8] and new formulas more precise and adequate to concrete have been proposed $[9,10]$, because it connects to the evaporation of an open surface of water rather than to a concrete surface, other researcher [11] ensures that the nomograph gives reasonable evaporation rates when the climatic data are taken with precise from jobsite.

\subsection{Shorter time set}

Due to the acceleration of the hydration reactions of hot climate concreting, setting time will be reduced by the action of high temperatures. Climatic conditions influence setting time, and wind is most influential parameter compared to the action of temperature, relative humidity and adjuvants (water reducer and retarder) [12, 2]. Which, shortens the time available for transport, placing and finishing. 


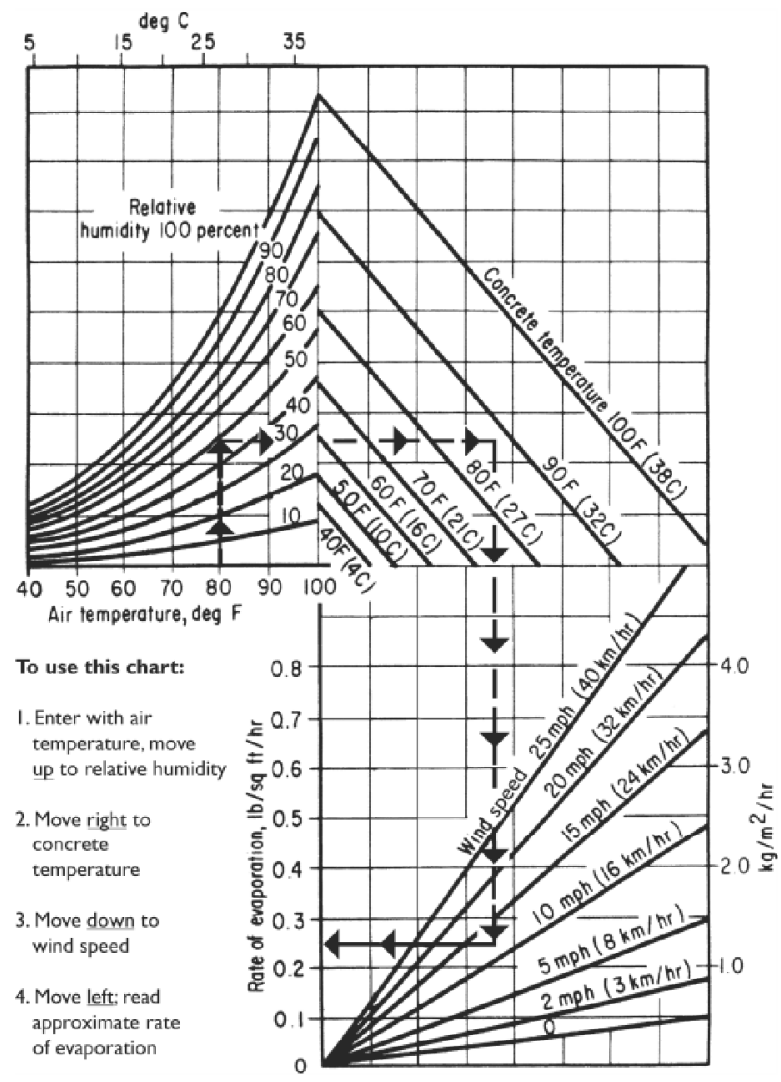

Fig. 1. ACI nomograph for estimating rate of evaporation of surface moisture from concrete [1].

\subsection{Plastic shrinkage}

If the climatic conditions (temperature, relative humidity and wind) are severe, such as the hot and arid climate and the form of the structure has a large free surface (such as slabs and floors), water will evaporates from the surface more rapidly than bleeding rate (i.e. the rate of rise of water), which will create capillaries pores between the solid particles (Fig. 2.); and as a result, tensile stress will act to bring the walls of the capillaries pores closer together (Fig. 3).

The hydrostatic tensile stress results from the concavity of the meniscus in the water-air interface. This hydrostatic stress increases when the diameter of the meniscus decreases. If this surface tension created by the evaporation of water from the concrete in the plastic state is greater than the tensile strength of the concrete, concrete will crack due to plastic shrinkage.

This cracks can have a length from 1 to $2 \mathrm{~cm}$ to 1 to $2 \mathrm{~m}$, with a depth that can penetrate the slabs, with depths greater than $23 \mathrm{~cm}$, and thicknesses of 0.1 to $3 \mathrm{~mm}$ [13]. It is clear that, plastic shrinkage cracks weaken the structure, allow the penetration of water, making rebar vulnerable to corrosion and reduce the durability. 


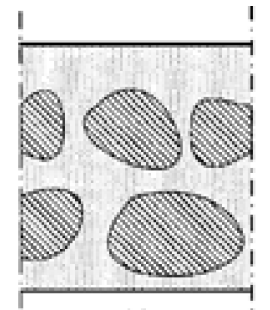

(a)

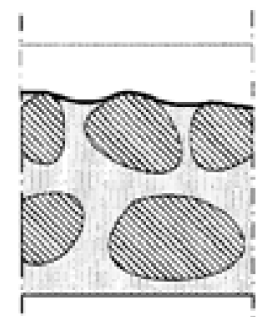

(c)

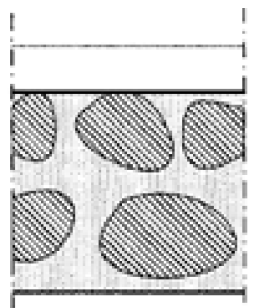

(b)

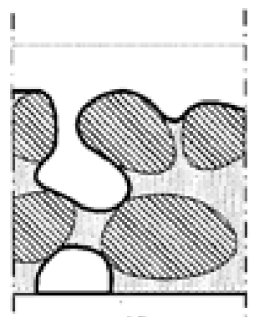

(d)

Fig. 2. Diagram of capillary stress in a cement matrix, (a) initial state, (b) loss of water due to evaporation, (c) formation of water menisci on the surface of the concrete, and (d) The opening pressure due to excessive evaporation.

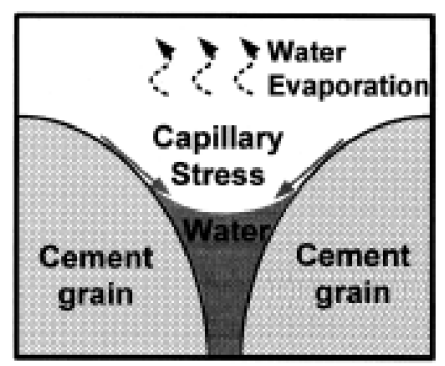

Fig. 3. Graphic representation of the liquid between two spherical particles.

\subsection{Rise of temperature and thermal cracking}

After demoulding of a structural concrete elements its surface will cool more quickly than its interior. Due to thermal contraction, the surfaces will be under traction and the inside will be compressed. If the tensile stresses on the surfaces exceed the tensile strength, the concrete cracks [14]. Moreover, the high temperature of the interior of the concrete also favours self-desiccation cracking [6].

\subsection{Strength}

The hydration reactions of cement are thermally activated; i.e., they are accelerated by temperature. Which normally give great resistance, but this is true only at early age $(<2$ days). Some researches show $[15,16,17]$ that long-term strength (28 days) is reduced by accelerated hardening. Probably because the hydration product of concrete which has accelerated hardening is less dense than the hydration products of the concrete in normal temperature $\left(20 \pm 5^{\circ} \mathrm{C}\right)$. 


\subsection{Durability}

The high temperature of concrete affects the initial workability and the rate of loss of workability and consequently the tendency to add more water to the mixer in jobsite. This would lead directly to concrete that is more vulnerable to freeze-thaw, climatic conditions, sulphate attack and penetration of carbon dioxide and chloride solutions leading to reinforcement corrosion. The low workability resulting from high temperature can lead to low compaction which also leaves the concrete more vulnerable to deterioration [8]. Plastic shrinkage and thermal cracking at early ages are also classed as deterioration mechanisms for concrete because they allow moisture, carbon dioxide, oxygen or chlorides to easily access to concrete reinforcements.

\section{Verification of curing conditions at jobsite}

Conditions (such as: temperature, relative humidity and wind velocity) during the curing period should be estimated before construction. Activities during construction focus on verifying actual conditions and making adjustments to jobsite procedures.

\subsection{Evaporation conditions}

From climatic data, evaporation rates can be calculated to determine if critical evaporotion rates exist, using the ACI chart 305 shown in Figure 1.

In general, evaporation rates greater than $0.3 \mathrm{~kg} / \mathrm{m} 2 / \mathrm{h}$ will present problems. However, the exact thresholds depend on particular conditions of concrete bleeding at jobsite.

\subsection{Calculation of setting time}

Using the concrete placement temperature, setting start time can be estimated, as described in the following equation:

$$
T O S=T O S_{s t d} \cdot e^{R\left(\frac{1}{C T}-\frac{1}{S t d T e m p}\right)}
$$

TOS: setting time in jobsite temperature with the same unit as the standardized test

TOS $_{\text {std }}$ : set time under standard conditions, with any unit

$\mathrm{CT}$ : temperature of the concrete at jobsite $[\mathrm{K}]$

StdTemp: temperature of the concrete in laboratory $[\mathrm{K}]$

$\mathrm{R}$ : constant.

\section{Hot climate concreting procedures}

\subsection{Cooling of components}

The amount of heat contained in a body or mass of material is the product of its specific mass, heat and temperature. The various ingredients in a concrete composition are present in different masses and they have a large difference in specific heat. The temperature of the fresh concrete can be approximated to:

$$
T=\frac{0.22\left(T_{a} W_{a}+T_{c} W_{c}\right)+T_{w} W_{w}+T_{a} W_{w a}}{0.22\left(W_{a} W_{c}\right)+W_{w}+W_{w a}}
$$


Where:

$\mathrm{T}$ : the temperature of the fresh concrete,

Ta, Tc, Tw: the temperature of the granulates, cement and mixing water respectively, Wa, Wc, Ww, Wwa: weight of aggregates, cement, mixing water and free water on granulates in $\mathrm{kg} / \mathrm{m} 3$ respectively.

Cooling of granulates with naturally available cold water is often the least costly way to reduce the temperature of the concrete; And using artificially cooled water for mixing concrete and cooling granulates can sometimes provide as much or more cooling than crushed ice used as part of mixing water.

On large construction jobsite, it may be necessary to install two cement silos so that the time between delivery and use is extended to reduce the temperature of the cement. In order to reduce the temperature of the cement. The silo cladding should, whatever happens, be painted white to minimize the temperature due to solar rays.

\subsection{Production and deliverance}

Temperature reductions can be achieved by painting the concrete mixing plant and the mixing trucks in white. As an example, concrete in a clean white body can be approximately $1.5^{\circ} \mathrm{C}$ cooler than concrete in a red body based on a one-hour delivery time. The period between mixing and delivery should be kept to a minimum. The shipping of the mixing plant trucks should be carefully coordinated with the rate at which the concrete is placed to avoid prolonged stop at the jobsite before the trucks are unloaded. Extremely low temperatures can be achieved nitrogen [18], but the process is expensive.

\subsection{Placement}

The planning of the transport, placement, vibration and finishing of the concrete must aim at the fastest possible speed. It can be considerably advantageous to concreting at night where the components are probably at their lowest temperature. The temperature of the moulds, reinforcement and previous cast concrete can be reduced by shading it before the concreting operation. Fresh concrete should be protected by windbreaks especially in hot, arid climates. Freshly placed concrete should also be shaded from direct sun rays.

\subsection{Cure}

\subsubsection{Initial Cure}

The initial curing period is defined in ACI $308 \mathrm{R}$ as the period between the placement of the concrete and the application of the final cure. The appropriate time for application of the final cure is approximately the start time of setting.

The initial cure is achieved through the use of evaporation reducers [19] which are relatively new developed products specifically designed for excessive evaporation conditions (they reduce evaporation by up to $80 \%$ in the shade by windy weather and about $40 \%$ of the direct sunlight), generally are based on alcohol a recent research proposes a silicone-based evaporation retarder [20].

The procedures is to apply evaporative reducers (just after finishing) in sufficient quantity and frequency so that the concrete does not lose critical amounts of water by evaporation. Using equipment similar to that used to apply the curing products. The 
relatively common practice is to apply part or of the curing product very early after placement to serve as an effective evaporative reducing agent.

\subsubsection{Final cure}

The final cure period is defined as the time interval between the application of the initial cure and the end of the programmed cure. Final cure methods can be classified into three types:

\subsubsection{Curing product method}

Curing product method is normally the most economical method for curing large surfaces because the relatively low labour costs. After the application is accomplished satisfactorily, it requires little or no additional attention. The negative side to the use of curing product methods is the relatively complicated issues of choice and conformity specification that are frequently required, and the skill required to properly application.

The characteristics of the curing products are covered by ASTM C 309 and ASTM C 1315. Selection criteria for curing products include: water retention, colorants, drying time, type and quantity of solids, Volatiles Organic Compounds (VOC), compatibility with coatings. Each of these criteria is discussed below.

Water retention is the main property of curing products. It is measured according to ASTM C 156, which measures the loss of water after a fixed period (usually 72 hours) of exposure to standard drying conditions. The standardized water retention limit (ASTM C 309 ) is a moisture loss of $0.55 \mathrm{~kg} / \mathrm{m} 2$ (maximum). ACI $305 \mathrm{R}$ recommends reducing the limit to $0.39 \mathrm{~kg} / \mathrm{m} 2$ for hot weather concreting.

The standardized drying time in ASTM C 150 is 4 hours under prescribed laboratory drying conditions. Laboratory conditions represent an evaporation rate of approximately $0.43 \mathrm{~kg} / \mathrm{m}^{2} / \mathrm{h}$. The following empirical equation is useful for estimating the required drying time under drying conditions.

$$
\text { Drying time }=\text { ER-0.67 }
$$

ER: the evaporation rate (in $\mathrm{kg} / \mathrm{m}^{2} / \mathrm{h}$ ) estimated using the ICA 308 nomograph.

The white dye reflects sunlight and helps control of temperature in hot weather. In addition to these functional properties, the dye is a very strong indicator of the amount and uniformity of the application.

The curing agents give good results if applied after the setting time. The guides recommend the application after the disappearance of the surface brightness of the concrete, this practice can lead to poor performance. The application of the curing product in this way slows or stops the evaporation of the bleeding water, which accumulates under the membrane or dilutes the curing product. In both cases the membrane will be damaged and this performance may be reduced during the final cure period. In some cases this damage is visible as cracks or tears in the membrane.

There is no method to check the uniformity of uncolored curing product, but two approaches are potentially practical for white-colored curing products. Visual checking is the easiest practice. The controller looks for less whitish surfaces. The products of curing of whitish coloring conforms to ASTM C 309 and applied at a rate equal to $5 \mathrm{~m}^{2} / \mathrm{L}$, have a very whitish appearance. Any trace of gray is an indication of serious under-dosage. Portable reflectometers are marketed to evaluate the quality of the paint. These devices are effective for measuring the application of the whitish coloring product. 


\subsubsection{Water curing method}

The water cure method includes immersion, vaporization and burlap or other wet absorbent materials. The water curing method is generally considered to be the only effective cure method for avoiding internal drying cracking for concretes with low $\mathrm{E} / \mathrm{C}$ ratios (which becomes critical when $\mathrm{E} / \mathrm{C}$ is less than 0.4 ).

ASTM C 94 contains conditions on the mixing water and the curing water. The conditions on the burlap are more complicated.

Fogging can be applied at any time after placing as long as it is not as heavy to prevent runoff. Watering can not be tolerated before the setting time due to the danger of washing the cement fines. Absorbent materials should not normally be applied before to setting start time because of the danger of physically damaging the surface.

Water absorbent materials can be covered with plastic sheet to eliminate evaporation and to reduce the amount of water needed for an effective cure. The burlap can be impregnated on one side with an impermeable layer.

Extreme hot weather conditions can be a problem when using the water curing method. Laboratory research has shown that a concrete exposed to an evaporation rate greater than $1.4 \mathrm{~kg} / \mathrm{m} 2 / \mathrm{h}$ may develop a cooling gradient above a depth of 50 millimeters above $13^{\circ} \mathrm{C}$. Covering wet absorbent materials with plastic overlay will significantly prevent evaporative cooling.

Typical advice is that any concrete is inspected at least once a day or more often if conditions permit, and if the found concrete is dry, the situation is corrected and an additional day is added to the required cure.

\subsubsection{Curing with plastic sheet cover}

This method is simple and relatively free of compliance with standards. This method is probably impractical for large surfaces and/or windy conditions, but can be very practical for smaller surfaces. Some customers do not allow the use of plastic cover directly against the concrete surface due to the non-regular coloring that sometimes develops.

ASTM C 171 describes the specifications of the plastic sheet cover, and contains relatively simple requirements. Particular attention must be paid to the overlap of the sheets (50 mm).

Single sheets of polyethylene work well for water conservation, but the use of this type of material can result in non-homogeneous colorization of the surface of the concrete. For this reason, some organisms do not allow curing with plastic sheets. Laminated plastic sheets/burlap are also manufactured to avoid this problem. White colored covers are available, which help to control the temperature by reflecting sunlight.

The plastic sheets must be applied after the start time of setting. As in the water cure method, daily visual inspection is the normal method of verification. If dry areas are found, the situation is corrected and an additional day is added to the required cure.

\section{Recommendations}

Developing countries are generally the hottest areas in the world, and the concrete industry develop very fast, because of the need of more infrastructures and buildings, this lead to hot climate concreting, understand hot climate negative effect on fresh and hardened concrete and hot climate procedures is primordial for realizing durable concrete, for that following recommendations can be drawn: 
- Most important problems of hot climate concreting for fresh concrete, are plastic shrinkage, excessive evaporation and early stiffing.

- Most important problems of hot climate concreting for hardened concrete, are strength drop on long term, rebar corrosion and reduced durability.

- Estimate and control of climatic conditions on jobsite is primordial.

- When evaporation rate is critical use hot climate concreting procedures.

- Keep cool as possible concrete components.

- Paint with all equipment to reduce its temperatures.

- Place concrete in the coolest period of the day.

- Use initial cure by using evaporation retarder or use curing product.

- Use adequate final cure method according to the characteristics the element.

- If any lack of cure is observed add another day to the cure period.

\section{References}

1. Murdock L. J., Brook K. M. and Dewar J. D. Concrete Materials and practices; Edward Arnold edition; London (1991)

2. El Rayyes M. S. Remedies to rapid setting in hot-weather concreting; in:

Admixtures for concrete. Improvement of properties symposium RILEM; Barcelona (1990)

3. Awad K. W., MazenH. and FakihR. Quality Control and Innovations in materials/ Hot-Weather Concreting. Proceedings, ACI Fifth International Conference, Canun, Mexico (2002)

4. Al hozaimy A.M. Effect of retempering on the compressive strength of readymixed concrete in hot-dry environments, Cement \& Concrete Composites, 29: 124127 (2007)

5. Al-KubaisyM.A. and PalanjianA.S.K. Retempering Studies Of Concrete In Hot Weather, RILEM Proceeding: Properties of Fresh Concrete, Hanover, West Germany (1990)

6. Kay E.A. Hot and cold weather concreting, in: Advanced Concrete Technology, Concrete Properties Edited by J. Newman, B. S. Choo, Elsevier (2003)

7. Ait-Aider H., Hannachi N.E., Mouret M. Importance of $\mathrm{W} / \mathrm{C}$ ratio on compressive strength of concrete in hot climate conditions; Building and Environment 42: 2461-2465 (2007)

8. BerhaneZ. (1984), Evaporation of Water from Fresh Mortar and Concrete at Different Environments, ACI Journal, November-December.

9. Uno P. J. Plastic Shrinkage Cracking and Evaporation Formulas, ACI Materials Journal; July-August: 365-375 (1998)

10. Al-Fadhala, M., and Hover, K. C. Rapid Evaporation from Freshly Cast Concrete and the Gulf Environment, Construction and Building Materials, V. 15, No. 1, Jan., pp. 1-7 (2001)

11. Kenneth C. Hover. Evaporation of Water from Concrete Surfaces, ACI Materials Journal/September-October (2006)

12. Ahmadi B. H. Initial and final setting time of concrete in hot weather, Materials and Structures/Matériaux et Constructions, Vol. 33, October, pp. 511-514 (2000)

13. Neville AM. Propriétés des bétons, Eyrolles (2000)

14. Chatterji S. Probable mechanisms of crack formation et early ages of concretes: A literature survey, Cement and Cconcrete Research. Vol. 12, pp. 371-376, 
USA (1982)

15. Mamillan M. Recherches expérimentales sur l'accélération du durcissement du béton par le chauffage. Cement and Concrete Research. Vol. I, pp. 211-223 (1971)

16. Mouret M., BascoulA. and Escadeillas G. Drops in concrete strength in summer related to the aggregate temperature. Cement and Concrete Research, Vol. 27, No. 3, pp. 345-357, 1997. Pergamon, Elsevier Science USA (1997)

17. Bella N. Traitement thermique de béton de sable. Mémoire de magistère, USTO-MB, Oran (2004)

18. Aitcine P., Shipping J., Byung G. K., Pierre C., Nkinama B., et Petrov N. L'interaction ciment /superplastifiant cas des PNS, Bulletin LCPC N/ 223, juillet/ Août (2001)

19. William A. Cordon \&Derle Thorpe. Controle of rapid drying of fresh concrete by evaporation controle, Journal of the American Concrete Institute, August, pp. 977985 (1965)

20. Bella Nabil, AsrounAissa and Bella IlhamAguida, The Use of a New Type of Evaporation Retardant Based on Silicone in Hot Climate Concreting, XIII-ICCCInternational Congress on the Chemistry of Cement, Madrid, Spain, 3-8 July, (2011)

21. Bella Nabil, Asroun Aissa and Bella Ilham Aguida, Use of a New Approach (Design of Experiments Method) to Study Different Procedures to Avoid Plastic Shrinkage Cracking of Concrete in Hot Climates, Journal of Advanced Concrete Technology, 9(2) 149-157 (2011) 